Buletin JSJ, 1 (1), 2019, 37-43

Available online di: http://ejournal-balitbang.kkp.go.id/index.php/JSJ/index

\title{
KEGIATAN PENYULUHAN PERIKANAN DI KECAMATAN GEBANG KABUPATEN CIREBON
}

\section{THE ACTIVITIES OF FISHERIES EXTENTION AT GEBANG, CIREBON}

\author{
Nurhadi Ali Mustaqim ${ }^{1}$, Yenni Nuraini ${ }^{1}$ \\ Jurusan Penyuluhan Perikanan, Sekolah Tinggi Perikanan, \\ Jalan Cikaret No. 02 Bogor, 16001 \\ Email : alikendal52@gmail.com
}

\begin{abstract}
ABSTRAK
Kecamatan Gebang merupakan salah satu kecamatan di Kabupaten Cirebon yang memiliki potensi perikanan yang cukup tinggi. Hal tersebut di dukung oleh sumber daya alam yang sangat mendukung kegiatan perikanan dengan adanya pesisir laut pantura menjadikan kecamatan ini sebagai lokasi agrowisata dan agribisnis perikanan. Besarnya potensi perikanan di daerah ini menjadikan penyuluhan tentang perikanan menjadi salah satu aspek penting yang dapat menunjang peningkatan pemberdayaan potensi perikanan seperti kelompok budidaya garam, kelompok nelayan, kelompok pembudidaya ikan di Kecamatan Gebang Kabupaten Cirebon. Penyuluhan perikanan memiliki peran strategis dalam pembangunan kelautan dan perikanan yang berkelanjutan, sebagai sistem pendidikan non formal berperan dalam transformasi perilaku pelaku utama dan pelaku usaha dalam pengembangan usaha kelautan dan perikanan yang lebih baik. Kegiatan penelitian yang dilaksanakan di Kecamatan Gebang antara lain perencanaan, pelaksanaan (aksi penyuluhan), dan evaluasi. Kegiatan perencanaan meliputi pengumpulan data potensi perikanan dan penyusunan program kerja yang akan dilakukan. Pelaksanaan (aksi penyuluhan) yang dilakukan meliputi pertemuan kelompok, kunjungan kelompok, pendataan kartu kusuka, pendampingan program bantuan dari dinas, dan demonstrasi cara pengolahan hasil perikanan. Kegiatan evaluasi dilakukan sebelum dan sesudah pelaksanaan aksi penyuluhan, aspek yang dinilai meliputi aspek pengetahuan dan sikap dengan instrument evaluasi berupa kuisioner. Berdasarkan hasil evaluasi penyuluhan diketahui terjadi peningkatan pada aspek pengetahuan sebesar $25,9 \%$ dan aspek sikap sebesar $75,6 \%$.
\end{abstract}

Kata kunci: Penyuluhan perikanan, Kegiatan penyuluhan

\begin{abstract}
Gebang is a of Cirebon Regency that has a high fishery potential. It is supported by natural resources that are very supportive of fishery activities with the coastal pantura make this district as a location for agro tourism and agribusiness fisheries. The amount of potential fisheries in this area makes counseling about fisheries become one of the important aspects that can support increased empowerment of fishery potential such as salt farming group, fishermen group, fish farmers group In the Gebang of Cirebon. Fisheries counseling has a strategic role in the development of sustainable maritime and fisheries, as a non-formal education system plays a role in transforming the behavior of key actors and business actors in the development of marine enterprises and Better fisheries. The fishery extension activities conducted in Gebang include planning, implementation (counseling action), and evaluation. Planning activities include collecting the potential data on fisheries and the preparation of work programs to be conducted. Implementation activities (counseling actions) conducted include group meetings, group visits, card data collection, mentoring assistance programs from the service, and demonstration of the way the processing of fishery results. Evaluation activities are carried out before and after the implementation of counseling actions, aspects assessed include aspects of attitude, knowledge and attitude, and skills with an evaluation instrument in the form of a questionnaire. Based on the results of the evaluation of counseling, it is known that there was an increase in the knowledge aspect by $25.9 \%$ and the attitude aspect by $75.6 \%$.Keywords: Fisheries extension. Fisheries counseling.
\end{abstract}

Keywords: fisheries extension, extension activities 
Buletin JSJ, 1 (1), 2019, 37-43

Available online di: http://ejournal-balitbang.kkp.go.id/index.php/JSJ/index

\section{PENDAHULUAN}

Penyuluhan merupakan suatu proses aktif yang memerlukan interaksi antara penyuluh dan yang disuluh agar terbangun proses perubahan perilaku. Dengan kata lain kegiatan penyuluhan tidak terhenti pada penyebarluasan informasi, dan memberikan penerangan. Tujuan penyuluhan perikanan adalah berubahnya perilaku petani yang mencakup perubahan dalam hal pengetahuan atau hal yang diketahui, perubahan dalam keterampilan atau kebiasaan dalam melakukan sesuatu dan perubahan dalam sikap dan mental kearah yang lebih baik dengan tujuan akhir penyuluhan adalah kesejahteraan hidup yang lebih baik. Kecamatan Gebang merupakan salah satu kecamatan di Kabupaten Cirebon yang memiliki potensi perikanan yang cukup tinggi. Hal tersebut di dukung oleh sumber daya alam yang sangat mendukung kegiatan perikanan dengan adanya pesisir laut Pantura menjadikan kecamatan ini sebagai lokasi agrowisata dan agribisnis perikanan. Kegiatan penyuluhan perikanan dilakukan di Kecamatan Gebang Kabupaten Cirebon Provinsi Jawa Barat sebagai wahana yang tepat untuk mengetahui secara langsung kondisi kelompok perikanan sebagai sasaran penyuluhan.

\section{BAHAN DAN METODE}

Penelitian ini dilaksanakan pada tanggal 24 Juni - 11 Juli 2019 di Kecamatan Gebang Kabupaten Cirebon Provinsi Jawa Barat. Metode yang dilakukan adalah magang dengan pengambilan data primer dan sekunder. Materi kegiatan berupa kegiatan penyuluhan yang dilaksanakaan dilapangan yang berupa penyelenggaraan kegiatan penyuluhan perikanan berupa perencanaan, pelaksanaan dan evaluasi penyuluhan. Responden penelitian ini adalah santri pondok pesantren untuk menambah soft skill dalam mengolah ikan lele. dilakukan penyuluhan berupa demonstrasi cara agar sasaran lebih tau dan bisa ikut praktek mengolah kripik ikan lele secara langsung. Kegiatan evaluasi penyuluhan perikanan dilakukan menggunakan kuisioner pre-test dan post test. Analisis data menggunakan analisis deskriptif dan tabulasi sederhana dengan grafik.

\section{HASIL DAN PEMBAHASAN}

\section{Keadaan Umum}

Kabupaten Cirebon merupakan salah satu wilayah pesisir di utara pulau Jawa yang terkenal dengan hasil lautnya dimana salah satunya adalah Kecamatan Gebang. Kecamatan Gebang terdiri dari 13 desa, dengan 9 desa yang memiliki potensi perikanan seperti penangkapan, pembudidaya, pengolahan dan petambak garam. Kecamatan Gebang memiliki luas kecamatan 3.374,674 Ha. Di Kecamatan Gebang memiliki dua musim yaitu musim kemarau dan musim penghujan. Pada tahu 2018, jumlah hari hujan sebanyak 115 hari per tahun dengan jumlah $2.268 \mathrm{~mm}$ per tahun. Letak geografis Kecamatan Gebang berada di Ketinggian tanah dari permukaan laut $0-2 \mathrm{~m}$, Suhu udara rata-rata $28^{\circ}-32^{\circ} \mathrm{C}$. Sumber daya alam di Kecamatan Gebang meliputi data luas sawah irigasi di Kecamatan Gebang dapat dilihat pada Tabel 1. 
Buletin JSJ, 1 (1), 2019, 37-43

Available online di: http://ejournal-balitbang.kkp.go.id/index.php/JSJ/index

Tabel 1. Data Luas Sawah Irigasi di Kecamatan Gebang

\begin{tabular}{clccccc}
\hline No & \multicolumn{1}{c}{ Desa } & Teknis & 1/2 Teknis & Pedesaan & $\begin{array}{c}\text { Tadah } \\
\text { Hujan }\end{array}$ & Jumlah \\
\hline 1 & Melaka Sari & 74 & - & - & 21 & 95 \\
2 & Playangan & 66 & - & - & 97 & 165 \\
3 & Gebang Ilir & 120 & 23 & - & - & 143 \\
4 & Gebang Mekar & 69,25 & - & - & - & 69,25 \\
5 & Gebang Kulon & 160 & 14 & - & 13 & 187 \\
6 & Kalipasung & 20 & 32 & - & 60 & 112 \\
7 & Gagasari & 56 & 40 & - & - & 96 \\
8 & Kalimaro & 91 & - & - & 9 & 100 \\
9 & Kalimekar & 56,51 & 16,23 & - & 12,26 & 85 \\
10 & Gebang Udik & 240 & 24 & - & - & 264 \\
11 & Gebang & 130 & 16 & - & 30 & 176 \\
12 & Dompyong. W & 100,138 & - & - & - & 100,138 \\
13 & Dompyong. K & 107,789 & - & - & 31 & 138,789 \\
\hline & JUMLAH & $1.290,687$ & 165,23 & - & 273,26 & $1.731,177$ \\
\hline
\end{tabular}

Sumber: BPS Kecamatan Gebang, 2018

\section{Sumber Daya Manusia}

Kecamatan Gebang merupakan daerah pesisir yang sebagian dari masyarakatnya bermata pencaharian dibidang perikanan. Mata pencaharian penduduk Kecamatan Gebang adalah sektor perindustrian, pertanian, nelayan, pendidikan, peternakan, perikanan, jasa dan perdagangan dan Pegawai Negeri Sipil. Jumlah Rumah Tangga Produksi (RTP) di Kecamatan Gebang dapat dilihat pada Tabel 2.

Tabel 2. Data RTP Perikanan di Kecamatan Gebang

\begin{tabular}{llccccc}
\hline \multirow{2}{*}{ No } & \multirow{2}{*}{ Desa } & \multicolumn{2}{c}{ Pembudidaya } & \multirow{2}{*}{ Pengolah } & \multirow{2}{*}{ Nelayan } & Petambak \\
& Air payau & Air tawar & Garam \\
\hline 1 & Melakasari & 280 & 1 & 10 & - & 25 \\
2 & Playangan & 80 & 5 & 15 & 210 & 20 \\
3 & Gebangilir & 45 & 1 & 5 & 916 & 45 \\
4 & Gebangmekar & 60 & 1 & 30 & 1792 & 40 \\
5 & Gebangkulon & 35 & 3 & 10 & 520 & 50 \\
6 & Kalipasung & 35 & 1 & - & 1125 & 30 \\
7 & Gebangudik & - & 3 & 30 & 1132 & - \\
8 & Gebang & - & 1 & - & 85 & - \\
9 & Gagasari & - & - & - & 240 & - \\
10 & Dompyong K. & - & 2 & - & - & - \\
\hline
\end{tabular}

Kecamatan Gebang dalam sektor perikanan mempunyai 2 orang penyuluh perikanan. ketenagaan penyuluh di Kecamatan Gebang dapat dilihat pada Tabel 3.

Tabel 3. Ketenagaan Penyuluh Perikanan di Wilayah Kecamatan Gebang

\begin{tabular}{ccccc}
\hline No & Nama & $\begin{array}{c}\text { Pendidikan } \\
\text { Terakhir }\end{array}$ & $\begin{array}{c}\text { Jenis } \\
\text { penyuluh }\end{array}$ & Keahlian \\
\hline 1 & Sodikin, S.Pi & S1 & PNS & Budidaya \\
2 & Rustoni & SD & Swadaya & Penangkapan \\
\hline
\end{tabular}


Buletin JSJ, 1 (1), 2019, 37-43

Available online di: http://ejournal-balitbang.kkp.go.id/index.php/JSJ/index

\section{Kegiatan Penyuluhan Perikanan}

Kegiatan penyuluhan perikanan ini bertujuan untuk meningkatkan pengetahuan, keterampilan dan sikap sasaran penyuluhan, mengidentifikasi masalah, pertukaran informasi antara penyuluh dan pelaku utama dalam menjalankan bisnisnya. dengan sasaran berupa kelompok perikanan menggunakan metode diskusi maupun ceramah bertempat di rumah anggota kelompok serta biaya yang dikeluarkan bersumber dari biaya sadaya kelompok yang bersaangkutan.

Kunjungan kelompok bertujuan untuk bertemu dan bersosialisasi kepada pelaku utama dan bertukar informasi mengenai permasalahan dan solusi permecahan permasalahan serta meningkatkan PKS pelaku utama. Kunjungan kelompok menggunakan metode anjang sana observasi langsung ke rumah pelaku tama. Dengan materi diskusi dan sharing kepada sasaran perorangan/kelompok.

Demonstrasi cara (demcar) pengolahan hasil perikanan berupa krpik lele dilakukan dengan tujuan meningkatkan PKS santri terhadap olahan dari ikan lele terutama kripik ikan lele. Sasaran demcar berupa santri dengan materi pengolahan kripik lele sumber biaya anggaran dari pondok pesantren. Evaluasi menggunakan kuisioner pre-test dan post tes. Kegiatan demcar dimulai dengan membuat lembar persiapan menyuluh, media yang digunakan berupa media asli berupa bahan dan peralatan serta media cetak berupa leaflet dan folder berisikan resep olahan dan manfaat ikan lele bagi kesehatan.

\section{Kegiatan Evaluasi}

Evaluasi penyuluhan merupakan alat atau tolak ukur dari kegiatan penyuluhan yang telah dilaksanakan. Berdasarkan evaluasi penyuluhan dapat diketahui apakah kegiatan penyuluhan telah dapat dilaksanakan dengan baik atau menghadapi suatu kendala dalam pelaksanan penyuluhan tersebut. Penyuluhan dikatakan berjalan baik apabila sasaran dapat menerima pesan yang diberikan. Kegiatan tersebut kemudian dievaluasi dan dibuat laporan kegiatan sebagai pertanggungjawaban.

Evaluasi kegiatan penyuluhan yang dilaksanakan pada saat akhir praktek menggunakan kuesioner dan hasilnya disimpulkan menggunakan penilaian pre-test dan post-test. Dari evaluasi tersebut diperoleh hasil evaluasi awal (pre-test) sebagai penilaian awal dan evaluasi akhir (post-test) sebagai penilaian akhir, sehingga dapat dilihat perubahan dan perbedaan antara evaluasi awal dan evaluasi akhir. Kegiatan evaluasi dilakukan terhadap 2 aspek, yaitu pengetahuan dan sikap (menggunakan skala likert)

\section{Pengumpulan data}

Data yang diperoleh pada aspek teknis yaitu data hasil peningkatan pengetahuan, sikap dan keterampilan pengolah dalam penerapan teknologi pengolahan melalui diversifikasi produk olahan. Teknik Pengumpulan data dan informasi dikumpulkan menggunakan alat bantu kuisioner evaluasi yang bersifat tertutup, terbuka, dan semi terbuka untuk menggali data dan informasi dalam kegiatan praktik akhir. Jenis pertanyaan yang diberikan dalam kuesioner dari aspek pengetahuan, sikap, dan keterampilan.

\section{Pengolahan data.}

Dalam melakukan pengolahan data akan digunakan metode analisis deskriptif dan analisis statistik. Metode analisis deskriptif ini digunakan untuk data kualitatif yang disajikan dalam bentuk uraian dan tabulasi sederhana seperti tabel, diagram, grafik, sedangkan metode analisis statistik digunakan untuk data kuantitatif. Pengolahan data pre-test aspek pengetahuan demcar pengolahan ikan lele dapat dilihat pada Tabel 4. 
Buletin JSJ, 1 (1), 2019, 37-43

Available online di: http://ejournal-balitbang.kkp.go.id/index.php/JSJ/index

Tabel 4. Pre-Test Aspek Pengetahuan Olahan Hasil Perikanan

\begin{tabular}{|c|c|c|c|c|c|c|c|c|c|c|c|c|}
\hline \multirow{2}{*}{ No } & \multirow{2}{*}{ Nama } & \multicolumn{10}{|c|}{ Pertanyaan } & \multirow[b]{2}{*}{ Jumlah } \\
\hline & & 1 & 2 & 3 & 4 & 5 & 6 & 7 & 8 & 9 & 10 & \\
\hline 1. & Fitria Anggraeni & 1 & 1 & 1 & 0 & 1 & 0 & 1 & 1 & 1 & 1 & 8 \\
\hline 2. & Dewi Safitri & 1 & 0 & 1 & 1 & 1 & 1 & 1 & 1 & 1 & 0 & 8 \\
\hline 3. & Fadma Wati & 1 & 1 & 1 & 1 & 1 & 0 & 1 & 0 & 1 & 1 & 8 \\
\hline 4. & Sulisti Awati & 1 & 1 & 1 & 1 & 0 & 0 & 1 & 1 & 0 & 0 & 6 \\
\hline 5. & Resmi Nur Z & 1 & 0 & 1 & 1 & 1 & 1 & 1 & 0 & 1 & 1 & 8 \\
\hline 6. & Safitri Rizkiah & 1 & 1 & 1 & 0 & 1 & 1 & 1 & 1 & 1 & 1 & 9 \\
\hline 7. & Siti Nur A & 1 & 0 & 1 & 1 & 1 & 1 & 1 & 1 & 1 & 1 & 9 \\
\hline 8. & Qori'atun & 1 & 1 & 1 & 0 & 1 & 0 & 1 & 0 & 0 & 0 & 5 \\
\hline 9. & Seiska Idelia S & 1 & 1 & 1 & 0 & 1 & 0 & 1 & 1 & 1 & 1 & 8 \\
\hline \multirow[t]{3}{*}{10.} & Azizah D & 1 & 1 & 1 & 0 & 0 & 1 & 1 & 1 & 1 & 1 & 8 \\
\hline & \multicolumn{11}{|c|}{ Jumlah } & 77 \\
\hline & \multicolumn{11}{|c|}{ Rata-rata } & 7.7 \\
\hline
\end{tabular}

Berdasarkan data tersebut, dapat disimpulkan bahwa tingkat pengetahuan pada saat evaluasi awal mengenai pengetahuan tentang olahan kripik ikan lele mencapai nilai rata-rata 7,7 dengan dengan predikat baik. Untuk mengetahui pencapaian sasaran dalam menerima materi, dilakukan post-test dengan soal yang sama dengan tujuan mengetahui peningkatan setelah demcar dilakukan Hasil post-test dapat dilihat pada Tabel 5.

Tabel 5. Post-test aspek pengetahuan olahan hasil perikanan

\begin{tabular}{|c|c|c|c|c|c|c|c|c|c|c|c|c|}
\hline \multirow{2}{*}{ No } & \multirow{2}{*}{ Nama } & \multicolumn{10}{|c|}{ Pertanyaan } & \multirow{2}{*}{ Jumlar } \\
\hline & & 1 & 2 & 3 & 4 & 5 & 6 & 7 & 8 & 9 & 10 & \\
\hline 1. & Fitria Anggraeni & 1 & 1 & 1 & 1 & 1 & 1 & 1 & 1 & 1 & 1 & 10 \\
\hline 2. & Dewi Safitri & 1 & 1 & 1 & 1 & 1 & 1 & 1 & 1 & 1 & 1 & 10 \\
\hline 3. & Fadma Wati & 1 & 1 & 1 & 1 & 1 & 1 & 1 & 1 & 1 & 1 & 10 \\
\hline 4. & Sulisti Awati & 1 & 1 & 1 & 1 & 0 & 1 & 1 & 1 & 1 & 1 & 9 \\
\hline 5. & Resmi Nur Z & 1 & 1 & 1 & 1 & 1 & 1 & 1 & 1 & 1 & 1 & 10 \\
\hline 6. & Shafitri Rizkiah & 1 & 1 & 1 & 1 & 1 & 1 & 1 & 1 & 1 & 1 & 10 \\
\hline 7. & Siti Nur A & 1 & 0 & 1 & 1 & 1 & 1 & 1 & 1 & 1 & 1 & 9 \\
\hline 8. & Qori'atun & 1 & 1 & 1 & 1 & 1 & 1 & 1 & 1 & 1 & 1 & 10 \\
\hline 9. & Seiska Idelia S & 1 & 1 & 1 & 0 & 1 & 1 & 1 & 1 & 1 & 1 & 9 \\
\hline 10. & Azizah D & 1 & 1 & 1 & 1 & 1 & 1 & 1 & 1 & 1 & 1 & 10 \\
\hline \multicolumn{12}{|c|}{ Jumlah } & 97 \\
\hline \multicolumn{12}{|c|}{ Rata-rata } & 9.7 \\
\hline
\end{tabular}

Berdasarkan data tersebut, dapat disimpulkan bahwa tingkat pengetahuan pada saat evaluasi ahir mengenai pengetahuan tentang olahan kripik ikan lele mencapai nilai rata-rata 9,7 dengan dengan predikat sangat baik. Pada evaluasi ahir mengalami peningkatan nilai ratarata ke angka 9,7 sehingga presikatnya dari baik menjadi sangat baik dan mengalami perubahan angka dari 7,7 menjadi 9,7. Dari perhitungan tersebut dapat dihitung perubahan pengetahuan.

Berdasarkan penghitungan hasil evaluasi diketahui terdapat perubahan nilai pada aspek pengetahuan sasaran sebesar 20 poin, perubahan nilai rata-rata pada aspek pengetahuan sebesar 2 poin, dan nilai peningkatan sebesar 25,9\%. Hal tersebut menunjukkan bahwa setelah adanya kegiatan penyuluhan terdapat perubahan pengetahuan bagi sasaran mengenai inovasi hasil perikanan bertupa keripik lele. 
Buletin JSJ, 1 (1), 2019, 37-43

Available online di: http://ejournal-balitbang.kkp.go.id/index.php/JSJ/index

Tabel 6. Pre-Test Aspek Sikap Olahan Hasil Perikanan

\begin{tabular}{clccccc}
\hline No & \multicolumn{1}{c}{ Pernyataan } & \multicolumn{5}{c}{ Jawaban Responden } \\
\cline { 3 - 7 } & SS & S & R & TS & STS \\
\hline 1 & $\begin{array}{l}\text { Keripik ikan lele adalah jenis olahan dari ikan yang } \\
\text { cara pembuaatannya mudah }\end{array}$ & 3 & 4 & 2 & 1 & 1 \\
2 & $\begin{array}{l}\text { Keripik ikan lele cocok digunakan untuk lauk makan } \\
\text { Keripik ikan lele tidak tahan lama } \\
3\end{array}$ & - & 4 & 2 & 3 & 1 \\
4 & $\begin{array}{l}\text { Ikan yang cocok digunakan untuk pembuataan } \\
\text { keripik yaitu ikan yang banyak durinya }\end{array}$ & - & - & 3 & 3 & 2 \\
5 & $\begin{array}{l}\text { Cara melumatkan daging ikan dalam pembuataan } \\
\text { abon dengan cara dikukus }\end{array}$ & 4 & 3 & 2 & 1 & - \\
6 & $\begin{array}{l}\text { Keripik ikan lele yang sudah matang yaitu berwarna } \\
\text { kuning }\end{array}$ & - & 3 & 4 & 2 & 1 \\
7 & $\begin{array}{l}\text { Dalam pembuatan keripik ikan lele agar rasanya } \\
\text { enak yaitu harus berani bumbu }\end{array}$ & - & 5 & 3 & 1 & 1 \\
8 & $\begin{array}{l}\text { Abon ikan lele bagus dikonsumsi oleh balita } \\
\text { Dalam pembuataan keripik ikan lele tanpa }\end{array}$ & 1 & 7 & 3 & 1 & - \\
$\begin{array}{l}\text { menggunakan bahan pengawet } \\
\text { Ikan yang tekstur dagingnya tebal cocok digunakan } \\
\text { untuk membuat abon }\end{array}$ & 2 & 5 & 2 & 1 & - \\
\hline$\quad$ Jumlah & 13 & 36 & 26 & 17 & 9 \\
\hline & Rata-rata & 1,3 & 3,6 & 2,6 & 1,7 & 0,9 \\
\hline
\end{tabular}

Berdasarkan perhitungan pada penilaian pre-test aspek sikap pelaku utama terhadap kegiatan Demcar pengolahan Hasil Perikanan berupa Keripik lele adalah bahwa pelaku utama secara garis besar ragu-ragu dengan perlunya pengetahuan dan keterampilan dalam pembuatan olahan keripik lele, yaitu dengan nilai yang dicapai jumlah rata-rata yaitu 33 atau sebesar $66 \%$ Sedangkan untuk mengetahui aspek sikap setelah kegiatan penyuluhan dilaksakan adalah dengan melakukan post-test aspek sikap dengan uraian pada Tabel 7.

Tabel 7. Post-test aspek sikap olahan hasil perikanan

\begin{tabular}{|c|c|c|c|c|c|c|}
\hline \multirow[t]{2}{*}{ No } & \multirow[t]{2}{*}{ Pernyataan } & \multicolumn{5}{|c|}{ Jawaban Responden } \\
\hline & & SS & $\mathrm{S}$ & $\mathrm{R}$ & TS & STS \\
\hline 1 & $\begin{array}{l}\text { Keripik ikan lele adalah jenis olahan dari ikan } \\
\text { yang cara pembuaatannya mudah }\end{array}$ & 3 & 6 & 1 & - & - \\
\hline 2 & $\begin{array}{l}\text { Keripik ikan lele cocok digunakan untuk lauk } \\
\text { makan }\end{array}$ & - & 7 & 2 & 1 & - \\
\hline 3 & Keripik ikan lele tidak tahan lama & 4 & 6 & - & - & - \\
\hline 4 & $\begin{array}{l}\text { Ikan yang cocok digunakan untuk pembuataan } \\
\text { keripik yaitu ikan yang banyak durinya }\end{array}$ & - & - & 1 & 6 & 3 \\
\hline 5 & $\begin{array}{l}\text { Cara melumatkan daging ikan dalam } \\
\text { pembuataan abon dengan cara dikukus }\end{array}$ & 4 & 5 & - & 1 & - \\
\hline 6 & $\begin{array}{l}\text { Keripik ikan lele yang sudah matang yaitu } \\
\text { berwarna kuning }\end{array}$ & 1 & 5 & 1 & 2 & 1 \\
\hline 7 & $\begin{array}{l}\text { Dalam pembuatan keripik ikan lele agar } \\
\text { rasanya enak yaitu harus berani bumbu }\end{array}$ & 2 & 7 & 1 & - & - \\
\hline 8 & Abon ikan lele bagus dikonsumsi oleh balita & 2 & 6 & 1 & 1 & - \\
\hline 9 & $\begin{array}{l}\text { Dalam pembuataan keripik ikan lele tanpa } \\
\text { menggunakan bahan pengawet }\end{array}$ & 3 & 7 & - & - & - \\
\hline 10 & $\begin{array}{l}\text { Ikan yang tekstur dagingnya tebal cocok } \\
\text { digunakan untuk membuat abon }\end{array}$ & 3 & 5 & 1 & 1 & - \\
\hline & Jumlah & 22 & 54 & 8 & 12 & 4 \\
\hline & Rata-rata & 2,2 & 5,4 & 0,8 & 1,2 & 0,4 \\
\hline
\end{tabular}


Available online di: http://ejournal-balitbang.kkp.go.id/index.php/JSJ/index

Berdasarkan perhitungan pada penilaian post-test aspek sikap pelaku utama terhadap kegiatan demcar pengolahan hasil perikanan berupa keripik lele, dapat dilihat bahwa adanya perubahan dan peningkatan aspek sikap pada pelaku utama, bahwa pelaku utama secara garis besar setuju dengan perlunya pengetahuan dan keterampilan dalam pembuatan kripik ikan lele, yaitu dengan nilai yang dicapai jumlah rata-rata yaitu 37,8 atau sebesar $75,6 \%$. Dari hasil perhitungan tersebut, maka dapat disimpulkan bahwa kegiatan penyuluhan berpengaruh terhadap perubahan sikap pada sasaran. Kesimpulan evaluasi : reponden (sasaran) mengarah ke setuju dan terdapat perubahan positif setelah adanya demonstrasi cara.

\section{KESIMPULAN DAN SARAN}

Hasil penelitian menunjukkan bahwa melalui kegaiatan penyuluhan tentang pengolahan keripik ikan lele terjadi peningkatan pada aspek pengetahuan dan aspek sikap pada responden. Saran dari penelitian ini yaitu perlu diadakan kegiatan penyuluhan secara intensif dan berkelanjutan agar usaha perikanan dapat di tingkatkan untuk menambah penghasilan para responden.

\section{DAFTAR PUSTAKA}

Mardikanto, Totok. 2003. Redefinisi dan Revitalisasi Penyuluhan Pembangunan, dalam Membentuk Pola Perilaku Manusia Pembangunan (Ed. Ida Yustina dan Adjat Sudradjat). Bogor: IPB Press.

Peraturan Menteri Pendayagunaan Aparatur Negara NO: PER/19/M.PAN/10/2008 Tentang Jabatan Fungsional Penyuluh Perikanan dan Angka Kreditnya. Jakarta.

Poernomo, S.H. 2005. Penyuluhan Perikanan Dalam Era Perubahan. Departemen Kelautan dan Perikanan Pusat Pendidikan dan Pelatihan Perikanan. Jakarta.

Rivai dan Razi. 2010. Dasar-dasar Penyuluhan. Modul Diklat Dasar Fungsional Penyuluh Perikanan Terampil. Kementerian Kelautan dan Perikanan Pusat Pelatihan Kelautan dan Perikanan: Jakarta.

Slamet, M. 2003. Perspektif Ilmu Penyuluhan Pembangunan Menyongsong Era Tinggal Landas Di dalam Membentuk Pola Perilaku Manusia Pembangunan. Bogor: IPB Press.

Undang-undang No. 16 Tahun 2006 tentang Sistem Penyuluhan Pertanian, Perikanan dan Kehutanan. Kementrian Kelautan dan Perikanan. Jakarta 